\title{
Analysis of the Motive Mechanism of User Innovation Based on System Dynamics
}

\author{
Tong-Tong ZHENG ${ }^{1, a}$, Qiong-Jie ZHOU ${ }^{2, b,{ }^{*}}$ \\ 1,2 Wuhan Donghu University, 301 wenhua Road, Jiangxia District, \\ wuhan, 430212, Hubei, China \\ appllztt@163.com, ${ }^{\mathrm{b}}$ Katharine7878@163.com \\ ${ }^{*}$ Corresponding author
}

Keywords: User innovation, Motive mechanism, System dynamics.

\begin{abstract}
Open innovation was promoted to the national macro strategic level. In the background of open innovation, user is one of the most innovative groups. The motive mechanism of user innovation is complicated, involving users, enterprises, government and other subjects. Based on the theory of system dynamics (SD), this paper constructs a model of the motive mechanism of user innovation after analyzing the dynamic factors of user innovation, and simulates this model by Vensim. The result indicates that user innovation contributes to improving the industry innovation performance and social innovation level.
\end{abstract}

\section{Introduction}

With the rapid development of science and technology, and the rising of the information age, innovation has become to be an impetus of promoting industrial development and economic growth, and technology innovation has become the key to improve enterprise's core competitiveness. In the meanwhile, with the arousal of user's innovation consciousness and the renewal of social marketing concept, users have the ability and willingness to innovate. User-centered innovative approach has gradually become the research hotspot of academia, and received extensive attention from enterprises.

The concept of user innovation was first proposed by Eric von Hippel formally in 1988, which has been a ground-breaking pioneering work, even though quite a bit of research has demonstrated the existence of user innovation both in industrial fields and consumer products[1]. User innovation is a main mode of innovation which is opposite to innovation activities undertook by manufacturers, and users are the dominant innovators deriving benefits from using the developed or modified products and services [2]. About the definition of user innovation, there is no consensus view in academic field yet. Regarding the perception of functional sources of innovation, user is one of the most important sources of innovation, as manufacture and supplier. Therefore, user innovation could be defined as innovative activities undertaken by users, especially in the phase of idea generation. In the domain of user innovation, users are the source of innovative idea, and actively engage in developing and modifying products for the purpose of meeting their own needs.

In consideration of the importance of user innovation in enterprises, this paper aims to analyze the motive mechanism of user innovation by using the method of System Dynamics, based on the current study.

\section{Analysis on Dynamic Factors of User Innovation}

Users are always motivated to innovate as the source of innovation. However, the drivers of user innovation are fairly mixed. From the aspect of users, there are three layers of inner drivers are involved. First, in the setting of manufacture-based innovation, manufacturers, who are constrained by a series of objective factors such as the costs of information access, the heterogeneity of user needs, the efficiency of innovation, users' changing preferences and manufacturers' biases, etc., would fail to identify user needs precisely and thoroughly, and then prefer to offer products that are 
designed to meet the demands of a large market segment. As a result, a considerable portion of users are seriously dissatisfied. For this reason, the most important and direct driver for users to innovate is to satisfy their own idiosyncratic needs. Second, users' intrinsic motivations are also the pivotal drivers stimulate users to innovate. Users' intrinsic motivation consist of users' unique hobbies of devoting to searching new solutions for their needs, users' experiences of joyfulness and learning opportunities[2], and expectation of gaining reputations, social approval and the sense of achievement[3], etc. during the process of innovation, which are treasured by innovative users. Third, user innovation is also encouraged by users' innovation-related knowledge, knowhow and capabilities [4].

From the aspect of manufacturers, the most important driver for user innovation is that user innovation would offset the negative effects of sticky information. Sticky information is defined as "the information that is costly to acquire, transfer, and use in a new location". The stickiness is stated as the incremental expenditure required to transfer a given unit of information to a specified location in a form that can be accessed by a given information seeker; the cost is higher information stickiness is higher [5]. Therefore, the key reason why manufacturers implement user innovation strategy is to overcome information stickiness and reduce uncertainty and meet users' needs better.

From the aspect of external society, on one hand, the relevant incentives concern various information and communication technologies which make innovation-related knowledge and information, and high support[6] from outside world like capitals, technologies and others funded by manufacturers, and policies and institutions encouragement from government available to users [7]. On the other hand, user's perception of technical difficulty, particularity and complexity of the innovation project also plays as a significant driver of user innovation, the possibility of user innovation is high when user's perception of the targeted innovation is low-skilled.

\section{The Construction of the System Dynamics Model about User Innovation}

\section{Model Construction}

System dynamics (SD) is an effective tool, which is widely used as a decision support tool in solving the strategic decision problems of all areas. A system dynamics model includes state variables, rate variables and auxiliary variables. State variables describe the state of system element, rate variables describe how quickly the state variables change over time, and auxiliary variables supply necessary auxiliary information to explain the complex relationship between rate variables and state variables. In order to discuss the motive mechanism of user innovation further, combining with the characteristics of user innovation, this research constructs a System dynamics model of user innovation (system flow chart is shown in figure 1). This model includes three state variables, six rate variables and 21 auxiliary variables.

Enterprise investment decision (EID), user innovation decision-making (UID) and the number of innovative users (NIU) are the three state variables in the model. The Value-Added of User innovation (VAU) represents the diffusion effect of user innovation when enterprises input nothing to users. User Innovation Investment (UII) includes both the user's own investment and the research rewards (RR) and research fund (RF) from enterprises. New Product Revenue (NPR) refers to enterprise's revenue after the marketization of user innovation. 


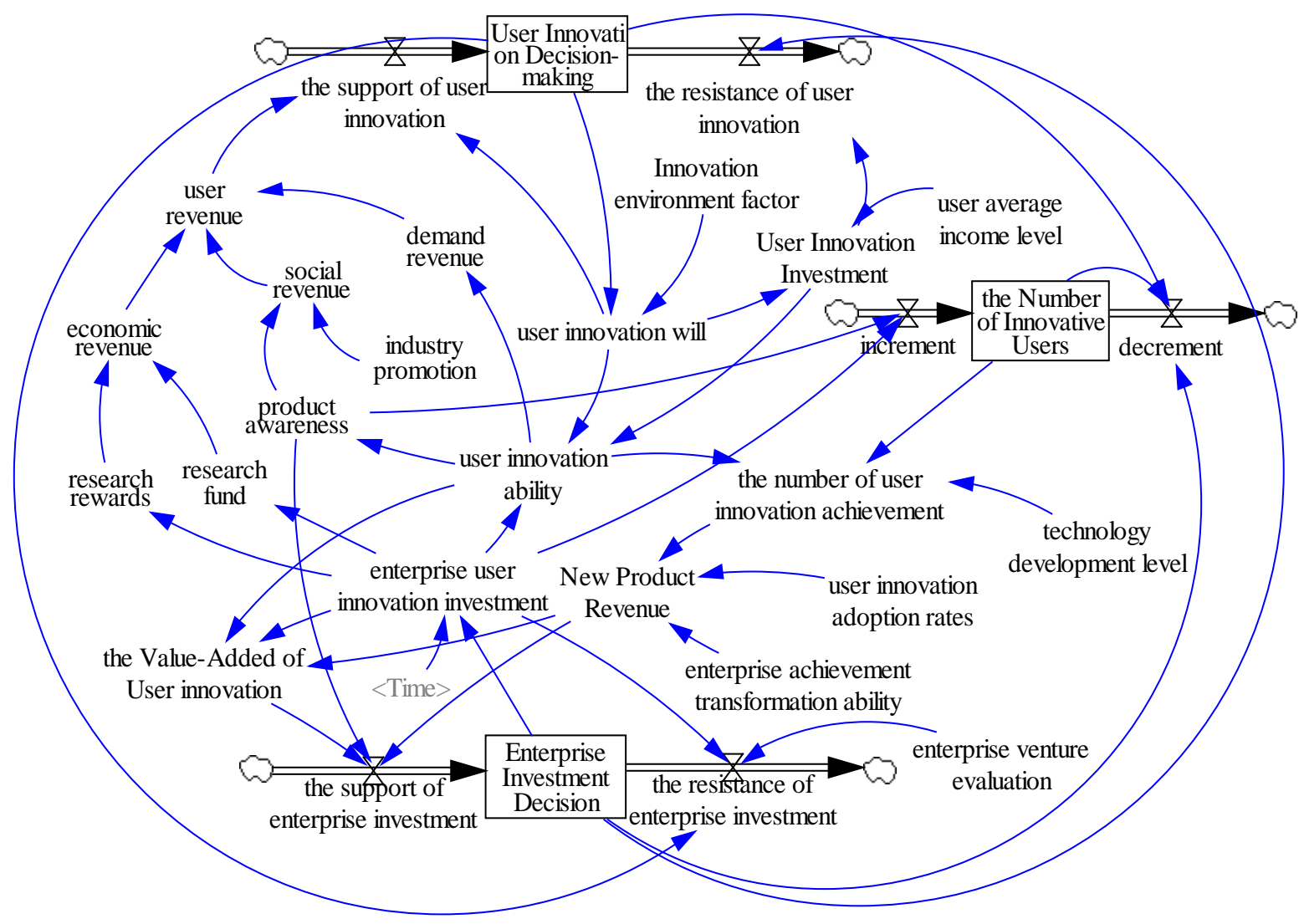

Fig.1 the System Flow Chart of the SD Model

\section{The Functional Relationship between Variables}

Based on the relationship among variables in figure 1, the function relationship among variables is built by the software of VENSIM. The main function relationship in the model is shown in table 1.

Among them, $\alpha$ is the Value-Added of User innovation's perception to the support of enterprise investment. $\beta$ is the basic strength of enterprise investment power. $\chi$ is enterprise user innovation investment's perception to the resistance of enterprise investment. $\delta$ is enterprise venture evaluation's perception to the resistance of enterprise investment. $\varepsilon$ is the UID's perception to the resistance of enterprise investment. $\eta$ is EID's perception to the resistance of user innovation. $\varphi$ is the user innovation will's impact strength to the support of user innovation. $\gamma$ is the UII's perception to the resistance of user innovation. $\mu$ is enterprise user innovation investment's perception to the increment of the number of innovative users. $\kappa$ is product awareness's perception to the increment of the number of innovative users. $\phi$ is user revenue's perception to the support of user innovation. $\pi$ is the total perception of three state variables to the decrement of the number of innovative users. 
Tab.1 The Meaning of Main Variables

\begin{tabular}{|c|c|c|}
\hline Variables types & Variables names & Function relationship \\
\hline \multirow{3}{*}{ State Variables } & $\begin{array}{l}\text { enterprise investment } \\
\text { decision(EID) }\end{array}$ & $E I D_{t}=S E I_{t}-R E I_{t}-E I D_{t-1}$ \\
\hline & $\begin{array}{l}\text { user innovation decision- } \\
\text { making(UID) }\end{array}$ & $U I D_{t}=S U I_{t}-R U I_{t}-U I D_{t-1}$ \\
\hline & $\begin{array}{c}\text { the number of innovative } \\
\text { users(NIU) }\end{array}$ & $N I U_{t}=I_{t}-D_{t}-N I U_{t-1}$ \\
\hline \multirow{6}{*}{ Rate Variables } & $\begin{array}{l}\text { the support of enterprise } \\
\text { investment(SEI) }\end{array}$ & $S E I=(U V A / \alpha+P A-N P R)+\beta$ \\
\hline & $\begin{array}{l}\text { the resistance of enterprise } \\
\text { investment(REI) }\end{array}$ & $R E I=(E U I / \chi+E V E / \delta-U I D / \varepsilon)$ \\
\hline & $\begin{array}{c}\text { the support of user } \\
\text { innovation(SUI) }\end{array}$ & $S U I=U R / \phi+U I W * \varphi$ \\
\hline & $\begin{array}{l}\text { the resistance of user } \\
\text { innovation(RUI) }\end{array}$ & $R U I=U I I / \gamma-E I D / \eta$ \\
\hline & increment(I) & $I=P A^{*} \kappa-E U I / \mu$ \\
\hline & decrement(D) & $D=(U I D * E I D * N I U) / \pi$ \\
\hline \multirow{14}{*}{$\begin{array}{l}\text { Auxiliary } \\
\text { Variables }\end{array}$} & new product revenue(NPR) & $N P R=A T A * N U I * I A R$ \\
\hline & $\begin{array}{l}\text { the value-added of user } \\
\text { innovation(UAV) }\end{array}$ & $U A V=(U I A * \varpi+N P R * \theta) /(E U I+\rho)$ \\
\hline & product awareness(PA) & $P A=U I A^{*} o$ \\
\hline & $\begin{array}{c}\text { enterprise user innovation } \\
\text { investment(EUI) }\end{array}$ & $E U I=\sigma+v^{*}$ Time $-\omega^{*}$ EID \\
\hline & user revenue(UR) & $U R=E R+S R+D R$ \\
\hline & user innovation will(UIW) & $U I W=I E F * U I D$ \\
\hline & user innovation investment(UII) & $U I I=\varsigma^{*} U I W * A I L$ \\
\hline & $\begin{array}{c}\text { the number of user innovation } \\
\text { achievement(NUI) }\end{array}$ & $N U I=N I U * T D L * U I A / \xi$ \\
\hline & user innovation ability(UIA) & $U I A=U I W^{*}(E U I+U I I / \psi) / \vartheta$ \\
\hline & economic revenue(ER) & $E R=R R+R F$ \\
\hline & social revenue(SR) & $S R=P A^{*} I P$ \\
\hline & demand revenue(DR) & $D R=\tau * U I A$ \\
\hline & research rewards(RR) & $R R=E U I / \lambda$ \\
\hline & research fund(RF) & $R F=E U I / v$ \\
\hline
\end{tabular}

\section{Model Simulation}

\section{Setting of Initial Parameters and Constants}

Before system simulation, the variables and constants in the SD model must be evaluated, including the initial parameters of constants and state variables. On the basis of interview, combined with the expert experience and the current situation of user innovation in our country, the initial value of relevant parameters and constants are set. Then, simulate the model on the set background, and predict the running situation (initial parameters as shown in table 2). In order to facilitate the dimensional unity and system simulation, assuming that these parameters are the dimensionless variables. In addition, according to the status quo of user innovation in our country, take the enterprise achievement transformation ability (ATA) as 2, user average income level (AIL) is 10000, user innovation adoption rates (IAR) is 0.4, enterprise venture evaluation (EVE) is 1, innovation environment factor (IEF) is 0.2, technology development level (TDL) of 4, industry promotion (IP) is 3 . 
Tab.2 the Setting of Other Parameters

\begin{tabular}{|c|c|c|c|}
\hline Variables name & Numerical value & Variables name & Numerical value \\
\hline$o$ & 0.8 & $\alpha$ & 10 \\
\hline$\beta$ & 1 & $\chi$ & 200 \\
\hline$\delta$ & 4 & $\varepsilon$ & 20 \\
\hline$\eta$ & 10 & $\varphi$ & 2 \\
\hline$\gamma$ & 800 & $\mu$ & 25 \\
\hline$\pi$ & 50 & $\varpi$ & 10 \\
\hline$\theta$ & 1000 & $\rho$ & 10 \\
\hline$v$ & 24.657 & $\omega$ & 23.047 \\
\hline$\psi$ & 10000 & $\vartheta$ & 10 \\
\hline$\tau$ & 0.9 & $\sigma$ & 2 \\
\hline$v$ & 1.2 & $\lambda$ & 1000 \\
\hline$\varsigma$ & 0.2 & $\xi$ & 100 \\
\hline$\kappa$ & 5 & $\phi$ & \\
\hline
\end{tabular}

\section{Simulation Analysis}

This study selected Vensim software as a simulation tool. Based on the above model design and parameter selection, set the INITIAL TIME as 0, the FINAL TIME as 10, TIME STEPT as 0.125, and Units for TIME is Year. Suppose that, in a user innovation system, the initial state of enterprise investment decision is 0 , the user input decision-making is 5, innovative user number is 100 . Simulate the system, the result is shown in figure 2.

(1) User innovation decision-making, the number of innovative users and user innovation will go up steadily after a short-term decline, which indicates that the main purpose of innovative users is to meet their own needs. Once their needs are met, user innovation decision-making, the number of innovative users and user innovation will present a downward trend. However, due to the incentive from enterprises and external environment, user innovation decision-making, the number of innovative users and user innovation will in the long run will gradually rise, and maintain stability.

(2) When the system reaches a steady state, the part of the innovative users is leading users. From the simulation results, the number of leading users is about $25 \%$ of the total users.

(3) Enterprise investment decision-making and new product revenue are rising increasingly. In fact, enterprise investment decision-making and new product revenue are highly relevant to each other. The higher the new product revenue, enterprise investment decision-making will be higher. As shown in Fig.2, new product revenue is lower in beginning, the growth of enterprise investment decision-making is slow; however, with the rapid growth of new product revenue, enterprise investment decision-making is increasing.

(4) User innovation ability is rising constantly, which indicates that user innovation ability is continuously enhanced because of coordinately functioning of enterprise investment decisionmaking and user innovation decision-making. Because user innovation decision-making finally presents a slow growth, enterprise investment decision-making plays an important role in promoting user innovation ability.

(5) To sum up, enterprise investment decision-making has a vital incentive effect on the improvement of user innovation decision-making, user innovation ability and user innovation will. Therefore, in order to promote the improvement of user innovation ability and the development of user innovation, enterprises are necessary to increase the investment on user innovation. 


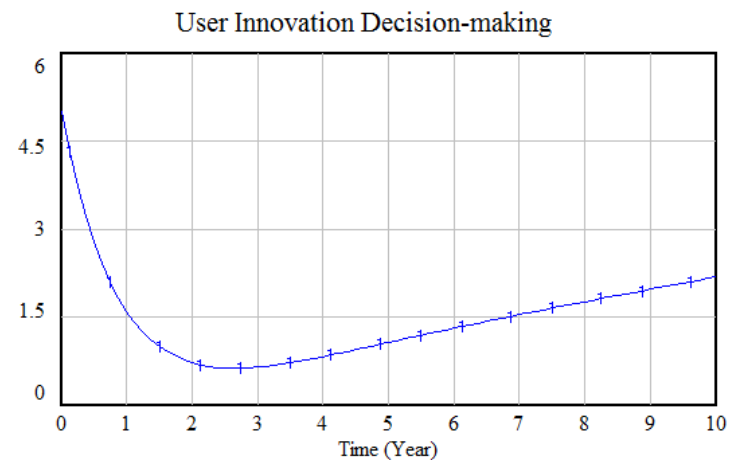

"User Innovation Decision-making" : Current

user innovation ability

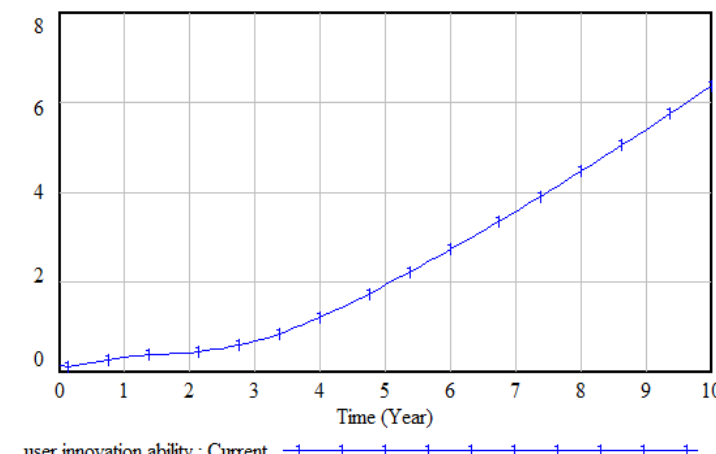

New Product Revenue

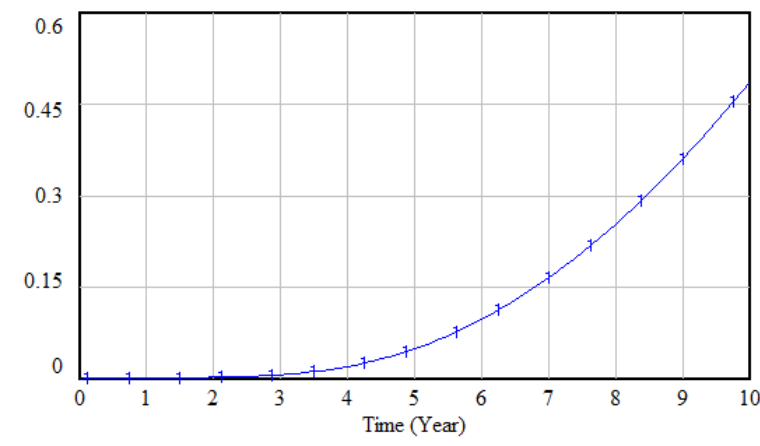

New Product Revenue : Current

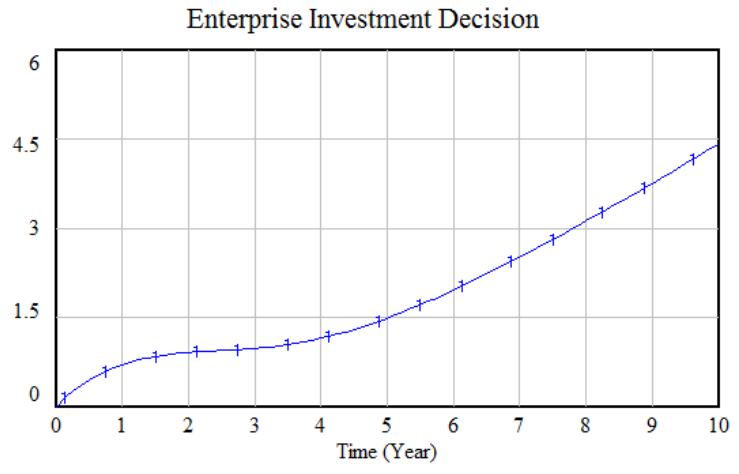

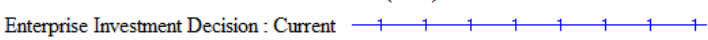

user innovation will

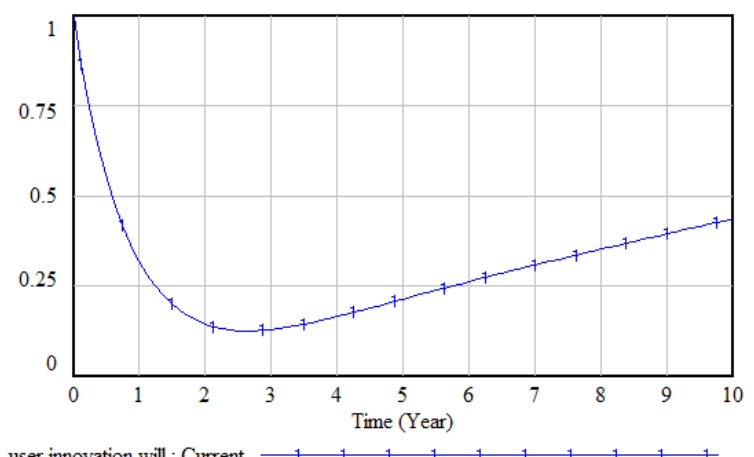

the Number of Innovative Users

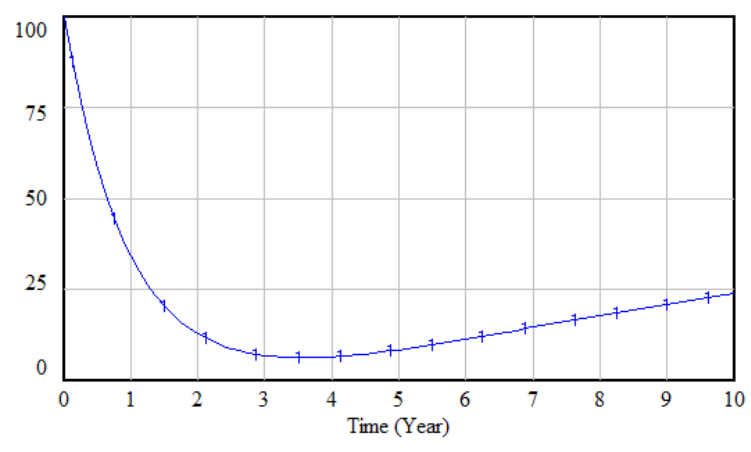

Fig.2 Simulation Results of SD Model of User Innovation

\section{Conclusion}

This study builds a system dynamics model of the mechanism of user innovation by the idea and method of system dynamics theory, and simulates the model by Vensim. Simulation results intuitively reflects that user innovation and the number of innovative users will keep in a stable state, and user innovation ability, enterprise investment and new product revenue are increasing constantly. Therefore, user innovation contributes to the improvement of enterprise innovation performance and social innovation level in a certain degree. In order to get more profit from user innovation, enterprises could build communication platform and community actively to extensively absorb collective wisdom, support and motivate user innovation, dig out innovative thinking, cultivate leading user groups, and develop a stable user knowledge base and database gradually. At the same time, government should give policy support, improve relevant systems and mechanisms, and encourage innovation.

\section{Acknowledgement}

This work was supported by the grants from Hubei Provincial Collaborative Innovation Centre of Agricultural E-Commerce(under Construction)(Wuhan Donghu university research [2015] No. 11 Document). 


\section{References}

[1] Tongtong ZHENG, Kefan XIE. Research of the origin, development and connotation [J]. Management Modernization, 2013(6):123-125 (In Chinese).

[2] von Hippel E. Democratizing Innovation [M].Massachusetts: the MIT Press, 2005

[3] Shah S. Sources and Patterns of Innovation in a Consumer Products Field: Innovations in Sporting Equipment [M]. MIT Sloan School of Management Working Paper \#4105 (March),2000.

[4] Nikolaus Franke \& Eric von Hippel. Satisfying Heterogeneous User Needs via Innovation Toolkits: the Case of Apache Security Software [J]. Research Policy, 2003, 32:1199-1215.

[5] Ogawa S. Does Sticky Information Affect the Locus of Innovation? Evidence from the Japanese Convenience Store Industry [J]. Research Policy, 1998, 26(7-8):777-790.

[6] Lars Bo Jeppesen. User Toolkits for Innovation: Consumers Support Each Other [J]. Product Innovation Management, 2005(22):347-362.

[7] Henkel J. \& Thies S. Customization and Innovation: User Innovation Toolkits for Simulator Software [J]. Munich: In Proceedings of the 2003 Congress on Mass Customization and Personalization (MCPC 2003), 2003. 